\title{
CRYPTOGENIC METASTASES IN UGANDA AFRICANS
}

\author{
A. C. Templeton, M. S. R. Hutt and O. G. Dodge, Kampala, Uganda \\ From the Department of Pathology, Makerere University, Kampala
}

It is quite common in Uganda for a patient to present with signs and symptoms of a malignant tumour of bone and it is important to distinguish primary from secondary neoplasms. In all such cases careful examination of likely primary sites is mandatory. If no primary site is apparent the distinction of a primary from a secondary neoplasm depends upon factors such as the relative frequency of various tumours, and the age, sex, anatomical site, radiological appearance, place and geographical location of the patient. In Western nations experience has accumulated which allows of a fairly accurate guess as to the nature of such skeletal tumours. In Uganda such background knowledge is often lacking because few clinicians see enough cases to build up experience of this problem. Because the relative frequency of primary tumours varies greatly around the world, it is likely that patterns of metastatic disease will also vary. This paper records our experience of biopsies taken from tumours of the skeleton when no primary neoplasm had been detected before operation.

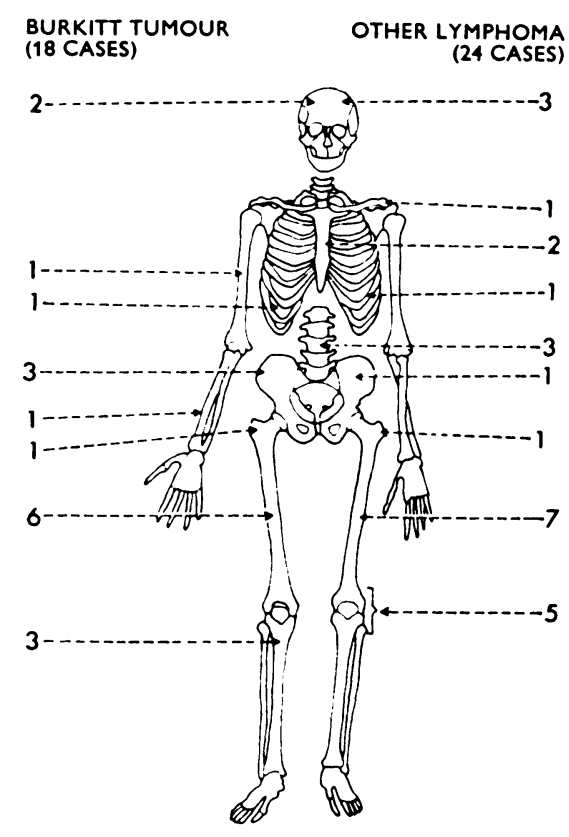

FIG. 1

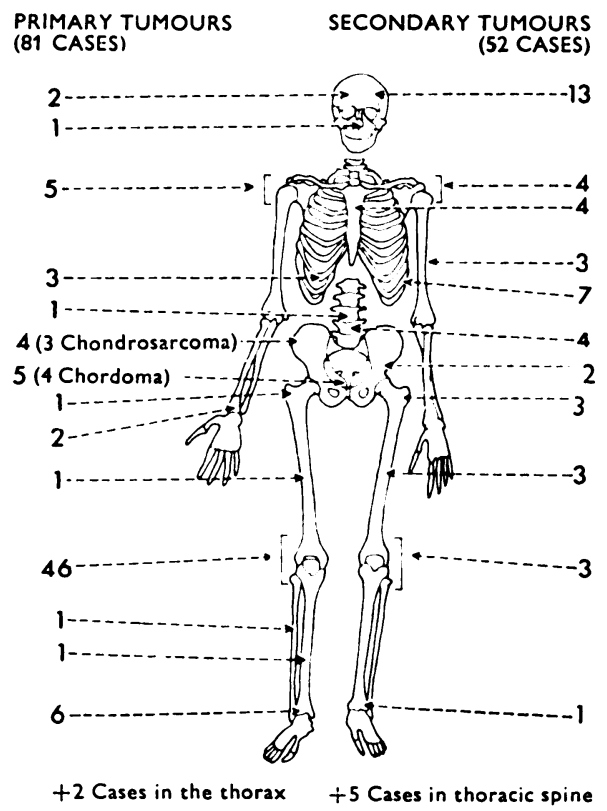

Fig. 2

Diagrams showing the frequency of involvement by various types of tumour at different sites.

\section{MATERIAL AND METHODS}

During the years 1964-68 the Department of Pathology at Makerere University College provided the only histological diagnostic service in Uganda. During this time approximately 40,000 biopsy specimens were examined; 9,000 were neoplastic in origin and 175 were malignant tumours of bone. The latter were classified into three groups: 1 ) lympho-reticular 
tumours; 2) secondary carcinoma; and 3) primary tumours of bone and cartilage, which included osteosarcoma, chondrosarcoma, malignant giant-cell tumour, chordoma and round cell-tumour of bone. Cases in which a primary tumour was discovered on clinical, radiological or haematological examination before biopsy have been excluded as have tumours of the maxilla and mandible because these bones were not the site of secondary neoplasms during this period and because the differential diagnosis included so many tumours not seen elsewhere (Ziegler, Wright and Kyalwazi 1971); in the five years thirty-five odontogenic tumours and 155 cases of Burkitt tumour of the jaw were seen. Benign tumorous conditions of bone have also been excluded because many such conditions are not submitted for histological diagnosis. This series, therefore, represents the clinical problem of a malignant tumour in bone needing biopsy to assist in diagnosis.

\section{RESULTS}

The site of involvement in each of the 175 tumours is shown in Figures 1 and 2. The age of the patients in the various tumour groups is shown in Table I, and the site of origin of secondary carcinomas which were discovered later is shown in Table II. Twenty-four cases are included as tumours of unknown origin because the primary site was never discovered conclusively, although in fourteen there was a very strong clinical or histological indication of the primary tumour. Six were thought to have arisen in the bronchus, three in the breast, two each from the prostate and liver, and one from the thyroid. If these diagnoses are accepted as correct, the order of likelihood of primary tumours with cryptogenic skeletal metastases is thyroid (twelve cases), liver (ten), prostate and bronchus (six each), breast and neuroblastoma (three each) and kidney and stomach (one each).

Probably the commonest tumour to present because of symptomatic bone disease is carcinoma of the prostate (about ten or twelve cases a year are seen at Mulago Hospital). This is true in most countries of the world. Carcinoma of the breast is another common primary site but since these two tumours can usually be diagnosed clinically they rarely fall within the chosen limits of this review. Occult primaries usually occur at other sites more difficult to examine.

\section{DISCUSSION}

It is difficult to find a series exactly comparable to ours because we have excluded cases in which the primary tumour was discovered before bone biopsy. Most series of metastatic bone tumours do not distinguish between those with occult or with evident primaries, or they record the frequency of bone metastases in patients with known primaries. For example, Jaffe (1958) investigated the incidence of metastatic tumour in cases of primary carcinoma of all sites, and found tumour in bone in over 70 per cent of cases. Abrams, Spiro and Goldstein (1950) studied 272 necropsy subjects who had died with known primary carcinomas and bone secondaries. The most frequent primary sites were breast (122), bronchus (fifty-two), large intestine (twenty-two) and prostate (sixteen); thyroid carcinoma was present in only five cases.

Meyer (1957) also studied a series of necropsies in which skeletal metastases of carcinoma were present: it was not made clear how many of the primary tumours had been undetected during life. In 320 cases the most frequent primary sites were bronchus (124), breast (fifty-six), prostate (fifty-three) and stomach (thirty-three); there were four thyroid carcinomas. It should be noted that these were both necropsy series.

Meyer argued, on the basis of his results, against the view that thyroid carcinoma was a frequent source of skeletal metastasis, and his conclusions may well be valid for a European population. But in Uganda the thyroid was the commonest source of metastatic skeletal carcinoma in our material, probably because of a high incidence of endemic goitre with many patients showing evidence of iodine deficiency in the thyroid at necropsy. Surveys of school children in different parts of Uganda have shown low iodine excretion in the urine (Follis and 
Connor 1966). Also the presence of a multinodular goitre makes it much more difficult to diagnose an underlying carcinoma. Nine of the eleven patients with an occult primary cancer of the thyroid were female and the sites of election for secondary deposits were the skull and upper end of femur (Table II). Four were follicular carcinomata, most being well differentiated

TABLE I

Age of Patients Presenting with Different Types of Skeletal Tumour

\begin{tabular}{|c|c|c|c|c|c|c|c|c|c|c|c|c|}
\hline \multicolumn{3}{|c|}{$\begin{array}{c}\text { Age } \\
\text { (years) }\end{array}$} & \multicolumn{2}{|c|}{ Burkitt (Males) } & \multirow{2}{*}{$\begin{array}{c}\begin{array}{c}\text { Other } \\
\text { lymphoma }\end{array} \\
1\end{array}$} & (Males) & \multicolumn{2}{|c|}{ Type of tumour } & \multicolumn{2}{|c|}{ Secondary (Males) } & \multicolumn{2}{|c|}{ Total (Males) } \\
\hline $0-9$ & . & . & 9 & (6) & & (1) & 7 & (2) & 3 & (2) & 20 & (11) \\
\hline $10-19$ & . &. & 7 & (6) & 8 & (8) & 35 & (20) & 4 & (3) & 54 & (37) \\
\hline $20-29$ & . & 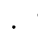 & 1 & (1) & 3 & (3) & 16 & (9) & 2 & (1) & 22 & (14) \\
\hline $30-39$ & . & . & 1 & (1) & 3 & (3) & 10 & (3) & 5 & (3) & 19 & (10) \\
\hline $40-49$ & . & . & & & 1 & (1) & 7 & (4) & 10 & (1) & 18 & (6) \\
\hline $50-59$ & . & 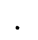 & & & 4 & (4) & & & 8 & (3) & 12 & (7) \\
\hline $60+$ & ${ }^{\circ}$ & . & & & 1 & & 2 & (1) & 11 & (9) & 14 & (10) \\
\hline $\begin{array}{l}\text { Adults } \\
\text { (age no }\end{array}$ & kno & & & & 3 & & 4 & (4) & 9 & (4) & 16 & (8) \\
\hline To & & . & 18 & (14) & 24 & (20) & 81 & (43) & 52 & (26) & 175 & (103) \\
\hline
\end{tabular}

TABLE II

Sites of Primary and Secondary Tumours

\begin{tabular}{|c|c|c|c|c|c|c|c|}
\hline \multirow{2}{*}{\multicolumn{2}{|c|}{ Primary tumour }} & \multirow{2}{*}{\multicolumn{2}{|c|}{ Number (Males) }} & \multicolumn{4}{|c|}{ Secondary site } \\
\hline & & & & \multirow{2}{*}{$\frac{\text { Skull }}{2}$} & \multirow{2}{*}{$\begin{array}{c}\begin{array}{c}\text { Thorax and } \\
\text { vertebrae }\end{array} \\
2\end{array}$} & \multirow{2}{*}{$\frac{\text { Femur }}{4}$} & \multirow{2}{*}{$\begin{array}{c}\text { Others* } \\
3\end{array}$} \\
\hline Thyroid & . & 11 & (2) & & & & \\
\hline Liver & . & 8 & (6) & 3 & 4 & & 1 \\
\hline Prostate & . & 4 & (4) & 1 & 3 & & \\
\hline Suprarenal & . & 3 & (2) & 2 & & & 1 \\
\hline Kidney & . & 1 & (1) & & 1 & & \\
\hline Stomach & . & 1 & $(-)$ & & & 1 & \\
\hline Unknown & . & 24 & (14) & 5 & 10 & 3 & 6 \\
\hline Total & . & 52 & (29) & 13 & 20 & 8 & 11 \\
\hline
\end{tabular}

* Includes 4 in the shoulder, 3 in the humerus, 2 in the pelvis and 2 in the tibia.

but, rather surprisingly, five showed a well marked papillary pattern. It is widely thought that follicular carcinoma is the most likely to metastasise to bone and that a papillary tumour is most likely to metastasise often to the cervical lymph nodes, but this does not seem to apply in Uganda.

VOL. 54 B, NO. 1, FEBRUARY 1972 
Hepatocellular carcinoma is a common tumour, with a rapid clinical course. The usual presenting symptoms of such a patient are extreme cachexia with much enlargement of the liver; metastases are seldom evident clinically. This impression was confirmed by necropsy studies which showed that about 50 per cent of cases show no evidence of extra-hepatic spread. However, in a few cases early metastasis to bone does take place, usually to the skull and vertebrae. Six of the eight cases recorded here were in men between the ages of thirty-five and sixty years. The histological appearance was usually of the hepatic or the clear-celled variety of liver cell carcinoma. In the hepatic type bile secretion sometimes aided diagnosis, but the clear-cell variant was difficult to distinguish from renal-cell carcinoma. The prognosis in patients presenting with enlargement of the liver is poor; most die within three or four months. However, patients presenting with metastases appear to have a rather better prognosis; the average interval between diagnosis and death was nine months. Whether this was because the tumour was discovered rather earlier in its natural history as a result of metastasis, or whether the difference in prognosis is a result of the different biological behaviour of such tumours has yet to be determined.

Carcinoma of the bronchus is uncommon in Uganda. Many cases are misdiagnosed, in most instances the symptoms being ascribed to tuberculosis. However, such tumours do occur (forty-five cases have been seen during the years 1964-68), and it is likely that they will become more frequent in future years as the habit of smoking increases. Proportionally carcinoma of the bronchus appears to involve bone as often as any other tumour.

Carcinoma of the kidney is unusual and secondary deposits are therefore rare. Tumours of the breast are also much less frequent than in Caucasian women and the primary tumour is usually obvious when skeletal metastases are seen. In general, tumours of the bowel and genitalia metastasise to bone infrequently.

Secondary tumours involve somewhat different sites from primary tumours of bone. Over 50 per cent of primary tumours occurred in the bones around the knee, whereas most secondary tumours were in the skull, ribs, vertebral bodies, sternum, pelvis and head of femur (Figs. 1 and 2). These sites accounted for 73 per cent of secondary tumours but only 21 per cent of primary bone tumours. The only site at which both secondary and primary tumours were seen often was the pelvis, where chordoma and chondrosarcoma are both common. Lymphomas followed closely the distribution of primary bone tumours, the femur being most often involved.

The commonest site for bone involvement in Burkitt's tumour was the jaw. In 6 per cent of cases there were clinically apparent masses in other bones, and microscopic involvement of the marrow is seen much more commonly. Apart from the jaw, the bone most often involved was the femur: such patients were usually rather older than those with jaw involvement (age range two and a half to thirty years with a mean of 10.4 years). Other lympho-reticular tumours involving bone included Hodgkin's disease, histiocytic lymphoma and acute myeloid leukaemia, which produced chloromata much more often than in European subjects.

The age of onset is different in primary and secondary bone tumours. Sixty-four per cent of patients with secondary bone tumours were over the age of forty, whereas 85 per cent of patients with primary bone tumours were under that age. Lymphoma was also found predominantly in younger people.

\section{SUMMARY}

1. Secondary tumours in bone are common in Uganda.

2. Of the five tumours which often give rise to bone metastases in Europe-breast, bronchus, thyroid, prostate and kidney-only the kidney is an unimportant site in Uganda, its place being taken by hepatocellular carcinoma. 
3. Most primary bone tumours occur around the knee whereas tumours of the skull, vertebrae and head of femur are very likely to be secondary. The thyroid was the most likely primary site for secondary tumours in women. In men the liver, bronchus and prostate were common primary sites.

Grateful thanks are due to the Cancer Research Campaign (British Empire Cancer Campaign) which has generously financed the documentation, review and follow-up of cancer in Uganda for many years.

\section{REFERENCES}

Abrams, H. L., Spiro, R., and Goldstein, N. (1950): Metastases in Carcinoma. Cancer, 3, 74.

Follis, R. H., and ConNor, D. H. (1966): Some Patterns of Urinary Iodine Excretion in Uganda. East African Medical Journal, 43, 114.

JAFFe, H. L. (1958): Tumors and Tumorous Conditions of the Bones and Joints, p. 593. London: Henry Kimpton. Meyer, P. C. (1957): A Statistical and Histological Survey of Metastatic Carcinoma in the Skeleton. British Journal of Cancer, 11, 509.

Ziegler, J. L., Wright, D. H., and Kyalwazi, S. K. (1971): Differential Diagnosis of Burkitt's Lymphoma of the Face and Jaws. Cancer, 27, 503.

VOI. 54 B, NO. 1, FEBRUARY 1972 